\title{
Population dynamics linked to glacial cycles in Cercis chuniana F.P. Metcalf (Fabaceae) endemic to the montane regions of southern China
}

\author{
Wanzhen Liu ${ }^{1}$, Jianguang Xie ${ }^{1}$, Hui Zhou ${ }^{1}$, Hanghui Kong ${ }^{2}$, Gang Hao ${ }^{1}$, Peter Fritsch ${ }^{3}$, \\ and Wei Gong ${ }^{1}$ \\ ${ }^{1}$ South China Agricultural University \\ ${ }^{2}$ Key Laboratory of Plant Resources Conservation and Sustainable Utilization, South \\ China Botanical Garden, Chinese Academy of Sciences, Guangzhou 510650, China \\ ${ }^{3}$ Botanical Research Institute of Texas, 1700 University Drive, Fort Worth, TX 76107, USA
}

June 22, 2020

\begin{abstract}
The mountains of southern China are an excellent system for investigating the processes driving the geographic distribution of biodiversity and radiation of plant populations in response to Pleistocene climate fluctuations. How the key mountain ranges in southern China have affected the evolution of narrowly distributed species is less studied than more widespread species. Here we focused on Cercis chuniana, a woody species endemic to the southern mountain ranges in subtropical China, to elucidate its population dynamics. We used genotyping by sequencing (GBS) to investigate the spatial pattern of genetic variation among 11 populations. Bayesian time estimation revealed that population divergence occurred in the middle Pleistocene, when populations in the Nanling Mts. separated from those to the east. Geographical isolation was detected between the populations located in adjacent mountain ranges, thought to function as geographical barriers due to their complex physiography. As inferred by ecological niche modeling and coalescent simulations, secondary contact occurred during the warm Lushan-Tali interglacial period in China, with intensified East Asia summer monsoon and continuous habitat available for occupation. Complex physiography plus long-term stable ecological conditions across glacial cycles facilitated the demographic expansion in the Nanling Mts., from which contemporary migration began. Our work shows that population genomic approaches are effective in detecting the population dynamics of narrowly distributed species. This study advances our understanding how glacial cycles have affected the evolutionary history of plant species in southern China montane ecosystems.
\end{abstract}

\begin{abstract}
The mountains of southern China are an excellent system for investigating the processes driving the geographic distribution of biodiversity and radiation of plant populations in response to Pleistocene climate fluctuations. How the key mountain ranges in southern China have affected the evolution of narrowly distributed species is less studied than more widespread species. Here we focused onCercis chuniana, a woody species endemic to the southern mountain ranges in subtropical China, to elucidate its population dynamics. We used genotyping by sequencing (GBS) to investigate the spatial pattern of genetic variation among 11 populations. Bayesian time estimation revealed that population divergence occurred in the middle Pleistocene, when populations in the Nanling Mts. separated from those to the east. Geographical isolation was detected between the populations located in adjacent mountain ranges, thought to function as geographical barriers due to their complex physiography. As inferred by ecological niche modeling and coalescent simulations, secondary contact occurred during the warm Lushan-Tali interglacial period in China, with intensified East Asia summer monsoon and continuous habitat available for occupation. Complex physiography plus
\end{abstract}


long-term stable ecological conditions across glacial cycles facilitated the demographic expansion in the Nanling Mts., from which contemporary migration began. Our work shows that population genomic approaches are effective in detecting the population dynamics of narrowly distributed species. This study advances our understanding how glacial cycles have affected the evolutionary history of plant species in southern China montane ecosystems.

KEYWORDS: Cercis chuniana, demographic modeling, geographic isolation, Pleistocene glacial cycles, secondary contact, Southern China mountainous ranges

\section{INTRODUCTION}

High physiographical heterogeneity is suggested to prompt rapid diversification in montane habitats because of the increased ecological opportunities afforded by frequent episodes of geographic isolation (Colin \& Ruth, 2006; Muellner-Riehl, 2019; Simpson, 1964). The high biodiversity of southern China is due in large part to the extreme physiographical heterogeneity of its mountain ranges (Fan et al. , 2018; Xu et al., 2017; Yang, Dick, Yao, \& Huang, 2016). Often oriented in either north-south or northeast-southwest directions (Hou, 1983; Wang, 1992a; Wang, 1992b; Ying, 2001), these topographically diverse ranges have been suggested to serve as either geographical barriers or colonization corridors for various plant species (Gong et al., 2016; Tian et al., 2018; Xiong, Wu, \& Zhang, 2019). Their local habitat uniqueness has been attributed to complex topography correlated with longitudinal or steep elevational gradients (Qiu, Zeng, Chen, Zhang, \& Zhong, 2013; Wang, Fang, Tang, \& Shi, 2012). The primary vegetation type of these mountains is subtropical evergreen broadleaved forest (STEBF), one of the largest continuous such forests in the world and well known for harbouring ancient relictual elements of the north-temperate biota (Qiu, Fu, \& Comes, 2011; Wang, Fang, Tang, \& Shi, 2012). Many of their plant species, predominantly endemics, exhibit high rates of local and rapid radiation (Hou et al., 2017; López-Pujol, Zhang, Sun, Ying, \& Ge, 2011) presumably arising within the last 5 million years, in line with both orogenic events and Pleistocene glacial cycles (Li et al. , 1979; Liu et al., 2013; Shi, Li, \& Li, 1998; Wang et al. , 2010). These characteristics make southern China an excellent system for investigating the processes driving the geographic distribution of biodiversity and radiation of plant populations in response to Pleistocene climate fluctuations.

Climatic oscillations associated with glacial cycles during the Pleistocene are also considered as an important factor driving the distribution pattern of biodiversity and shaping the demographic history of populations, particularly in montane regions (Hewitt, 2004; Li et al., 2019; Mesquita, Tillmann, Bernad, Rosemond, \& Suding, 2018; Svenningm, Normand, \& Skov, 2009). Although still under debate, considerable data are now available to support four glacial periods in eastern China (east to $105^{\circ} \mathrm{E}$ ) during the Pleistocene, i.e. the Poyang, Dagu, Lushan and Tali Glacials (Duan, $\mathrm{Pu}, \& \mathrm{Wu}, 1980$ ). In southern China, the degree of habitat connectivity is thought to have decreased during glacial periods, with vegetation belts lowering in elevation and contracting in geographic range, providing the opportunity for both geographical isolation and genetic divergence to occur (Shi, Cui, \& Su, 2006). Multiple glacial refugia correlated with centres of genetic diversity have been identified in southern China, out of which subsequent localized or rapid range expansions have been inferred (Chen et al., 2012; Gong, Chen, Dobes, Fu, \& Koch, 2008; Li, Shao, Lu, Zhang, \& Qiu, 2012; Qiu, Fu, \& Comes, 2011; Tian et al., 2015). Previous research has elucidated the scenarios involved with glacial and postglacial evolutionary history of plant species in southern China (Gong et al., 2016; Liu et al., 2012; Tian, Ye, Wang, Bao, \& Wang, 2020). However, most of this research has focused on widespread species and ignored how key mountain ranges might affect the evolution of narrowly distributed species.

Cercis chuniana F. P. Metcalf (Fabaceae: Cercidoideae; Azani et al., 2017) is a small tree or shrub endemic to the STEBF of southern China. It has a narrow geographical distribution, extending from the Wuyi and Eastern China Mountains westwards to the Nanling Mountains with increasingly larger population sizes and densities. Unique among Cercis species, it has an asymmetrical leaf blade (Chen, Zhang, Larsen, \& Vincent, 2010; Metcalf, 1940), which makes it easily identifiable morphologically. The species is resolved near the base of the Cercis phylogenetic tree, with an estimated age of 2.40 Ma (Fritsch et al. , 2018; Liu et al., unpublished data, 2020). As with its congeners in China, it exhibits an adaptation to mesic environments through its acuminate leaf blade apex (Fritsch et al. , 2018; Isely, 1975; Wunderlin Larsen, \& Larsen, 1981). 
Genotyping by sequencing (GBS) has been widely used as a genomic approach for investigating genetic diversity and population structure (Chen, Hou, Zhang, Pang, \& Li, 2017; Metzker, 2010; Niu et al. , 2019). Because it is based on genomic reduction with restriction enzymes, GBS does not require a reference genome to detect single nucleotide polymorphisms (SNPs). In combination with marker discovery and genotyping, GBS provides a rapid, high-throughput, and cost-effective tool for a genome-wide analysis for nonmodel species (Andrews, Good, Miller, Luikart, \& Hohenlohe, 2016; Davey et al. , 2011; Scheben, Batley, \& Edwards, 2017). Here, we used GBS and collected genome-wide SNPs for population genetic analyses of C. chuniana . We aimed to 1) investigate genetic diversity and population structure of the species, 2) elucidate its demographic history, and 3) use the data to infer the roles of mountain ranges in southern China and Pleistocene climatic fluctuations in driving its diversification and geographic distribution. We thereby hoped to gain a better understanding of the impact of this environment on the evolutionary history of narrowly distributed species.

\section{MATERIALS AND METHODS}

\subsection{Population sampling}

We collected 11 populations and 112 individuals of C. chunianafrom throughout the current geographic distribution of the species (Figure 1, Table 1). Anywhere from one to five populations were collected from each of the mountain ranges in southern China, including the Wuyi, Luoxiao, and Nanling Mountains. Populations WYS1 and WYS2 are located in the eastern and western parts of the Wuyi Mts., respectively. LXS1 is located in the southern end of the Luoxiao Mts. and LXS2 is located between the Wuyi Mts. and Luoxiao Mts. NLE1 and NLE2 are located in the eastern part of the Nanling Mts., whereas NLW1 through NLW5 are located in the western part of the Nanling Mts. (Figure 1, Table 1). We also collected 20 individuals from one population of C. chingii Chun located in Chichengshan in Zhejiang Province.

\subsection{Ecological niche modeling}

We used ecological niche modeling (ENM; Soberon \& Peterson 2005) to characterize the spatial distribution of suitable conditions for $C$. chuniana and locate potential distributional areas in conjunction with historical biological inferences. We based the analysis on high-resolution paleoclimate data inferred for the Last Interglacial (LIG, 0.14 $0.12 \mathrm{Ma}$ ), Last Glacial Maximum (LGM, [?] $0.02 \mathrm{Ma}$ ), Middle Holocene (MH, [?] $0.006 \mathrm{Ma}$ ), and current. Bioclimatic variables were downloaded from the WorldClim database (http://worldclim.org/download; Fick \& Hijmans, 2017) for the four different stages with 2.5-minute spatial resolution. The LIG, LGM, and MH data were obtained from circulation model simulation of the Community Climate System Model (CCSM) (Collins et al., 2006), which provides downscaled high-resolution estimates of the climate parameters (Hijmans, Cameron, Parra, Jones, \& Jarvis, 2005). We used the maximum entropy modeling method with Maxent v3.3.2 (Phillips, Anderson, \& Schapire, 2006). Herbarium specimen records of $C$. chuniana from nine herbaria (A, IBEC, IBK, IBSC, KUN, LBG, NMNH, PE and SCFI) as well as our sample collection locations were used to determine the locations of populations considered to occur at present. The analysis pipelines and parameter settings, including the occurrence points, current/past bioclimatic variables as well as the convergence threshold and maximum number of iterations were all as in Dai et al. (2011) and Gong et al. (2016). Model accuracy was assessed by evaluating the area under the curve (AUC) of the receiver-operating characteristic (ROC) plot (Phillips et al. , 2006), where scores higher than 0.70 were considered to show good model performance (Fielding \& Bell, 1997). This approach is thus conservative, identifying the minimum predicted area possible while maintaining zero omission error in the training dataset (Pearson, Raxworthy, Nakamura, \& Peterson, 2007). The most influential climate factors were also compared, including precipitation and temperature in each month or on average.

\subsection{DNA extraction, genotyping by sequencing (GBS), SNP calling and quality filtering}

Tender leaves of $C$. chuniana and $C$. chingii were sampled and placed into centrifuge tubes, which were instantly immersed in liquid nitrogen and stored at -80 . Leaf tissue was ground in tubes with glass beads with the tissue homogenizer Tissuelyser-96 (Shanghai Jingxin Industrial Development Co., Ltd). Total genomic DNA was extracted with the modified cetyl trimethyl ammonium bromide (CTAB) method (Doyle 
\& Doyle, 1986). DNA concentration was quantified with a Nanodrop spectrophotometer (Thermo Scientific, Carlsbad, CA, USA), and a final DNA concentration of $>30 \mathrm{ng} / \mu \mathrm{L}$ was used.

Genotyping by sequencing (GBS) is a streamlined workflow for generating reduced representation libraries for Illumina sequencing (Heffelfinger et al. , 2014; Ilut, Nydam, \& Hare, 2014; Melo, Bartaula, \& Hale, 2016). The genomic DNA was digested with a combination of Mse I and Nla III enzymes. Subsequent ligation to barcodes after multiplex amplification was constructed and the desired fragments were selected for GBS library construction in Novogene Co. Ltd. The Illumina HiSeq sequencing platform (Illumina, San Diego, CA, USA) was used for paired-end (PE) 150 sequencing. Further advanced analyses and DNA library assembly were performed to remove low-quality reads. Reads in fastq format were assembled by using STACKS v2.2 (Catchen, Hohenlohe, Bassham, Amores, \& Cresko, 2013) with one individual of Cercis glabra Pamp. as reference. BWA v0.7.8 (Li \& Durbin, 2009) and SAMtools v1.3.1 (Li et al., 2009) were used for sequence mapping and sorting. We used 132 individuals for SNP calling with Stacks. For population analysis, we extracted SNPs with a minor allele frequency (MAF) of at least 0.05 and a genotyping rate of at least $80 \%$ of individuals within populations. We also specified a maximum observed heterozygosity of $50 \%$ and a minimum number of five populations per locus.

\subsection{Phylogenetic analysis and divergence time estimation}

To reconstruct phylogenetic relationships among the 11 populations of $C$. chuniana, we employed a maximum likelihood (ML) analysis to generate phylogenetic trees using the SNPs extracted based on the GBS dataset. Cercis chingii was used to root the trees, as based on the results of Fritsch \& Cruz (2012). Analyses were performed on the high-performance computer cluster available in the CIPRES Science Gateway 3.3 (www.phylo.org; Miller et al. , 2015). The ML analyses were performed simultaneously with 1000 ML bootstrap pseudoreplicates in RAxML v8 (Alexandros, 2014). The model of nucleotide substitution was selected with the Akaike information criteria (AIC; Akaike, 1974) in PhyML-SMS (http://www.atgcmontpellier.fr/phymL/; Lefort, Longueville, \& Gascuel, 2017).

Divergence times within Cercis based on the fossil record suggested that C. chuniana originated 2.4 Ma (Fritsch et al. , 2018; Liu et al. , unpublished data, 2020). Therefore, to estimate the divergence time within C. chuniana, we used BEAST v2.4.7 (Bouckaert et al. , 2014) and applied the age of 2.4 Ma as the secondary calibration point with a normal prior distributions and standard deviations of $0.2 \mathrm{Ma}$, which covered the 95\% HPD range. The divergence time analyses were conducted with the GTR + G + I model and four rate categories, a Coalescent Constant Population prior, and the Strict Clock setting with uncorrelated and log-normal-distributed rate variation across the branches. We ran the MCMC simulations in BEAST for 10 million generations with parameters sampled every 1000th generation. We used Tracer v1.6 (Rambaut, Suchard, Xie, \& Drummond, 2014) to assess convergence and to check that the effective sample size (ESS) was $>200$ for each parameter. We discarded the first $10 \%$ of trees as burn-in with the mean node heights option, and then generated the maximum clade credibility (MCC) chronogram from the remaining trees with nodal mean heights and 95\% confidence time intervals with TreeAnnotator v2.4.7 (Bouckaert et al. , 2014) in BEAST. The final trees were edited with FigTree v.1.4.3 (http://tree.bio.ed.as.uk/software/figtree/; Rambaut, 2014).

\subsection{Genetic diversity, population assignment and admixture}

The number of alleles and allele frequencies for the selected SNPs were calculated with vcftools 0.1.16 (Petr et al. , 2011). To measure genetic diversity, we estimated expected heterozygosity ( $\mathrm{He}$ ) and observed heterozygosity ( $H o$ ). We used Arlequin v3.5 (Excoffier \& Lischer, 2010) to estimate genetic differentiation by calculating pairwise values of differences among populations $(F s t)$. To compare molecular diversity between and within populations, we used analysis of molecular variance (AMOVA) and a hierarchical analysis of subdivision (Excoffier, Smouse, \& Quattro, 1992; Weir, 1996; Weir \& Cockerham, 1984).

We estimated population genetic structure with a Bayesian Markov Chain Monte Carlo model (MCMC) implemented in FastStructure v1.0 (Raj, Stephens, \& Pritchard, 2014). We used the default setting with 10 -fold cross-validation on the 112 individuals of $C$. chuniana, testing for subpopulations $(K)$ ranging from 
1 to 11. The python script Choose $\mathrm{K}$ in FastStructure was used to choose the optimal $K$, i.e., the value that maximizes the marginal likelihood. Results were graphically represented and edited with Adobe Illustrator. We performed principal component analysis (PCA) using the PCA function in SNPRelate (Zheng et al., 2012) and visualized the results using the scripts of Tanya Lama (https://github.com/ECOtlama/SNPRelate.git) in the $\mathrm{R}$ package.

\subsection{Inference of demographic history}

For ancestral area reconstruction, we used seven groups of $C$. chuniana for S-DIVA (statistical dispersalvicariance analysis) analysis implemented in RASP v3.2 (Ronquist 1997; Yu, Harris, Blair, \& He, 2015). The analysis was based on the BEAST MCMC trees and the maximum clade credibility tree derived from the Bayesian analysis with BEAST and TreeAnnotator (Matuszak, Muellner-Riehl, Sun, \& Favre, 2016). With this method, the frequencies of an ancestral area at a node in the ancestral reconstructions are averaged over all trees. Dispersal or vicariance events were also detected with S-DIVA.

We applied coalescent simulations with the program fastsimocoal2 (FSC2; Excoffier, Dupanloup, HuertaSanchez, Sousa, \& Foll, 2013) to provide model evidence of divergence, secondary contact, bottleneck effects, and demographic expansion. The populations in the Nanling Mts., which formed a monophyletic group and showed a distinct geographic location, were considered as one group (NL), and the remaining populations as another (ES). We used easySFS (https://github.com/isaacovercast/easySFS) to transform SNPs into a folded site frequency spectrum (SFS), based on the construction of 10 demographic models with the two groups (Figure S2). The models are: without isolation (NIS), isolation only (IS), isolation followed by migration (MIG), bottleneck effect (BOT), or secondary contact (SEC). Models including ancient (AMIG) or recent migration (RMIG), bidirectional or one-way migration, and demographic expansion (EXP) were also applied. In each model, NL or ES were alternatively used as the split source that was subjected to each scenario. We estimated effective population size $(N e)$, time $(T)$ and migration rates in individual migrants per generation $\left(M_{N L-E S}\right.$ and $\left.M_{E S-N L}\right)$ for the two groups in each model from posterior distributions. To scale parameter estimates into real values, we used the substitution/site/generation mutation rate of $1.16 \times 10^{-7}$ based on our research (Liu et al., unpublished data, 2020), because no genomic mutation rate has been calculated for Cercis. We estimated a generation time of five years for $C$. chuniana based on estimates for its congeners (Aldworth, 1998; Chen \& Mao, 1999). We ran 100 replicate FSC2 analyses under each model with 10,000 simulations for optimal parameters and composite likelihood estimation. All 10 demographic models were compared (Figure S2, Tables S2-S4). The composite likelihood of arbitrarily complex demographic models under the given SFS was calculated by using best-fit models based on the Akaike information criterion (AIC). The models with the lowest AIC were chosen as the best fit of the data.

\section{RESULTS}

\subsection{Ecological niche modelling}

Evaluation of model performance based on both training and test sample data indicated that the models had high predictive power (AUC $=0.9976$ and 0.9966 , respectively). Results yielded a continuous geographical distribution of $C$. chuniana across several mountain ranges in southern China during the LIG (Figure 2a). In contrast, during the LGM the geographical distribution contracted into three fragmented areas (Figure 2b). We compared these data to a vegetation map of the LGM (http://intarch.ac.uk/journal/issue11/2/map/download_page_js.htm), based on which the three fragmented distribution areas were located mainly inside forest steppe (number 7 ) and partially in semi-arid temperate woodland or scrub (number 3) (Ray \& Adams, 2001). The geographical distribution of C. chuniana was inferred to have expanded widely during the $\mathrm{MH}$, occupying most of the Chinese subtropical region. No changes in the geographical distribution were evident between $\mathrm{MH}$ and current. Precipitation in April, May and June was revealed to be the most influential climate factor for suitable distribution range of $C$. chuniana (Table S1).

\subsection{Characterization and distribution of SNPs}


GBS produced 200.8 GB raw reads and 200 GB clean reads. High-quality tags were identified from 10,761,958 GB-PE reads. The sequence data was high quality with Q20 [?] 92.23\% and Q30 [?] 85.00\%. The mean $\mathrm{G}+\mathrm{C}$ content was $37.84 \%$. We detected 61,748 SNPs for C. chuniana with C. chingii as outgroup, among which 32,890 SNPs agreed with the SNP extraction criteria (Table S5). The data have been deposited in Figshare (DOI: XXX).

\subsection{Phylogenetic relationships and divergence times}

The phylogenetic analysis yielded monophyly for each population with mostly high bootstrap values (Figure 3). WYS1 was revealed to be positioned at the first-diverging branch, followed by the populations WYS2, LXS2 and LXS1. The populations in the Nanling Mts. formed a monophyletic group, with NLE2 and NLE1 in the eastern Nanling Mts. forming a clade separate from the others in the western Nanling Mts. The time of origin of C. chuniana was estimated as $2.36(95 \% \mathrm{HPD}=1.97-2.74)$ Ma during the early Pleistocene (Figure 4). WYS1 was first divergent from the remaining populations, followed by WYS2/LXS2 diverging from the rest ca. 0.85 Ma during the Poyang Glacial period. The divergence occurring between WYS2 and LXS2 was estimated as ca. 0.72 Ma, whereas the divergence between LSX1 and the populations in the Nanling Mts. ca. 0.68 Ma. Both divergence times arose within the third glacial period in China in Middle Pleistocene, although the exact glacial and interglacial time ranges are still under debate (Figure 4). Within the Nanling Mts., the eastern NLE1/NLE2 populations diverged from the western NLW1-NLW5 populations ca. 0.58 Ma, while NLW1 from the rest western populations ca. $0.51 \mathrm{Ma}$, both of which were estimated as occurring in the Dagu Glacial period (Figure 4). Population diversifications in Nanling Mts. range from 0.20 to 0.29 $\mathrm{Ma}$ in the western populations and from 0.35 to $0.37 \mathrm{Ma}$ in the eastern ones, respectively, the former of which is during the Lushan Glacial period and the latter in the Dagu-Lushan Interglacial period. Population diversifications in the east (WYS1-2 and LXS1-2) were calculated from 0.34 to $0.51 \mathrm{Ma}$, estimated spanning both the Dagu-Lushan Glacial and the Interglacial periods (Figure 4).

\subsection{Genetic diversity and differentiation}

The highest $H e$ was detected in NLW2 (0.38) followed by NLW5 (0.35); the lowest was detected in LXS2 (0.31; Table 1). The highest $H_{O}$ was detected in NLW1 (0.34) followed by NLW2 (0.33); the lowest was detected in LXS2 (0.19). On average, Heand $\mathrm{Ho}$ in the Nanling Mts. $(\mathrm{He}=0.33 ; \mathrm{Ho}=0.29)$ were comparable to those of the other populations in the east $(H e=0.32 ; H o=0.27)$. In FastStructure analysis, WYS1 separated from the remaining populations when $K=2$. WYS2 and LXS2 clustered as one group and separated from the remaining groups when $K=3$. Seven subpopulations $(K=7)$ were determined as the optimal clustering for $C$. chuniana (Figure 4). Differing slightly from the FastStructure result, the PCA analysis clustered LXS1 and LXS2 together and these were distinctly separate from the populations in the Nanling Mts. (Figure S1). Considering the FastStructure, PCA, and phylogenetic results together with the geographical locations of populations, we ultimately circumscribed seven groups of $C$. chuniana populations for further analyses: WYS1, WYS2, LXS1, LXS2, [NLE1 + NLE2], NLW1, and [NLW2 through NLW5]. Analysis of the molecular variance as based on the GBS data indicated significant genetic differentiation among populations $(F s t=0.99, P=0.00)$, of which the variation among the seven groups accounted for $96.28 \%$ of the total variation (Table 2 ).

\subsection{Inference of demographic history}

Six vicariance events (V1-V6) among the geographical regions were inferred from the S-DIVA analysis (Figure 1). V1 is between WYS1 and the rest of the populations. V2 is between WYS2 and LXS2, located in the western Wuyi Mts. and southern Luoxiao Mts., respectively. V3 is between WYS2/LXS2 and the rest of the populations, including LXS1 and the populations in the Nanling Mts. V4 is between LXS1 and the rest of the populations. V5 is between the eastern and western Nanling Mts., separating [NLE1 + NLE2] and [NLW1 through NLW5], whereas V6 is between NLW1 and NLW2 through NLW5. Across the six vicariance events, the eastern populations diverged from the rest of the species first, and the western populations later.

The best fit model for the demographic analysis with FSC2 is model SECEXP, indicating an isolation model followed by secondary contact (SEC) and demographic expansion (EXP; Table 3, Figure 5, S2, Table S2-S4). 
The time scale of 548,000 generations (2.74 Ma) was confirmed based on the lowest AIC value. Based on the mutation rate, we converted the genome-wide estimates of nucleotide diversity into effective population sizes. The current effective population sizes of the Nanling Mts. (NL) and eastern regions (ES) are $N e_{N L}=$ 57,495 and $N e_{E S}=14,955$, respectively. From the current effective population size, the ancestral effective population size was calculated as $N e_{A N C}=755,955$ (Table 3, Figure 5, Table S3). Using the ancestral effective population size, we converted the divergence time between NL and ES into the number of generation times, $T_{D I V}=319,472$ generations ago, i.e., about 1.6 Ma. Secondary contact (SEC) was estimated at ca. $T$ SEC $=0.10$ Ma. This time is within the Lushan-Tali Interglacial period in China (Duan, Pu, \& Wu, 1980; Zhu, Liu, \& Jackson, 2004), when temperature increased and was ca. 5 higher than at present (Figure 2). The ancestral effective population size of NL was estimated to be much smaller $\left(N_{\text {e-pre-exp }}=866\right)$ than at present. In contrast, the ES population sizes remained more or less constant (Table 3, Figure 5, Table S3). The migration rate $M_{N L-E S}(2.14)$ was much higher than $M_{E S-N L}(0.33)$, with migration occurring after NL and ES divergence.

\section{DISCUSSION}

\subsection{Genetic divergence between eastern and western populations}

The population divergence in the eastern portion of the geographic range of $C$. chuniana is estimated to be older (0.51-0.34 Ma) and with smaller population sizes than within the Nanling Mts., where more recent and rapid population diversification occurred (0.37-020 Ma) with larger population sizes (Figure 4). The phylogenetic analysis also revealed that populations of the Nanling Mts. formed a monophyly group and were separated distinctly from the eastern populations. This pattern agrees with the general pattern of genetic divergence observed between eastern and western China in other plant species with wide distributions (Chen, Deng, Zhou, \& Sun, 2018; Gong et al. , 2008; Ha, Kim, Choi, \& Kim, 2018; Hohmann et al., 2018; Lu et al. , 2018; Qiu, Guan, Fu, \& Comes, 2009). One main factor contributing to the differences of population divergence time and level of diversification between the east and west is likely to be the different orientations of mountain ranges (Chen et al. , 2018). The southwest-northeast orientation of the Wuyi Mts. and East China Mts. are thought to present geographical barriers blocking southward migrations in times of cooler climate or northward postglacial population expansion, which is disadvantageous for increasing population size and diversification, and may have contributed to an older divergence as is seen in the eastern populations (WYS1, WYS2, LXS1 and LXS2). Conversely, the north-south orientation of the Nanling Mts., allowing various elevational shifts of plant species, can facilitate gradual retreat from north to south and shortdistance migrations during glacial and interglacial periods, thus promoting more population diversification, larger population size and younger divergence as is seen in the populations of the Nanling Mts. (NLE1 and NLE2, and NLW1 through NLW5). Therefore, the orientation and physiography of the mountain ranges appear to have contributes to the geographic pattern of genetic variation between the eastern and western populations of C. chuniana .

\subsection{Geographical isolation and population divergence associated with Pleistocene climatic os-} cillations and mountain ranges

All populations are monophyletic and closely aligned with geographical regions (Figure 1, 3), suggesting that they evolved mostly via local diversification. This is thought to occur especially when geographic isolation plays a dominant role (Harrington, Hollingsworth, Higham, \& Reeder, 2018; Hughes, 2017; Hughes \& Atchison, 2015; Kadereit, 2017; Nevado, Contreras-Ortiz, Hughes, \& Filatov, 2018; Xing \& Ree, 2017). Analysis of the molecular variance with significantly high population divergence $(F s t=0.99, P=0.00)$ also indicates low inter-population gene flow (Table 2). Mountain ranges sometimes are considered as poorly conducive for facilitating long-distance dispersal, thus contributing to limited gene flow and geographic isolation (Oyama et al., 2018). In our study, isolation between WYS1 and WYS2 (V1) was attributed to the Wuyi Mts. acting as geographical barrier to separate the populations from each other (Figures 1, 3). The rising of Wuyi Mts. during the early Pleistocene has been reported to cause geographical isolation and genetic divergence for many species in southern China (Liu, 1984; Yan et al., 2013). Notably, the central Luoxiao Mts., with a north-south orientation, are assumed to serve as a geographic barrier particularly for 
east-west colonization. This appears to apply to LXS1 and LXS2 in the Luoxiao Mts., which are currently isolated from each of their eastern or western populations (V2 and V3) (Figures 1,3). We infer that the geographical isolation between the populations of the Nanling Mts. and those to the east (V4) has arisen through the lack of geographical corridors with a west-to-east orientation. Vicariance events also exist between the western and eastern (V5) as well as the middle and northwest (V6) populations within the Nanling Mts. The Nanling Mts. present a general north-south orientation, which we infer as disadvantageous for east-west colonization, thus contributing to vicariance involving V5. In contrast with the populations NLW2 5 , NLW1 is located alone on one ridge of the Nanling Mts. and geographically distant from the remaining populations, thus resulting in the vicariance involving V6. Therefore, the geographical barriers formed by the associated mountain ranges including the Wuyi, Luoxiao, and Nanling Mts. have directly limited long-distance colonization and are considered a major factor contributing to the historical isolation of C. chuniana populations (Jiang, Xu, \& Deng, 2019; Li et al. ,2019; Yang et al. , 2019). Similar patterns have been found in many other plant species with a wide distribution range in subtropical China, such as Machilus pauhoi(Zhu et al. , 2017), Loropetalum chinense (Gong et al. , 2016) and Liriodendron chinense (Shen, Cheng, Li, \& Li, 2019), all of which were analyzed with traditional molecular markers and data analysis.

Our study suggests that population divergence of $C$. chunianaoccurred in the Pleistocene and has been affected by the glacial cycles. These cycles periodically changed suitable habitat and are thought to have promoted range contraction and expansion coupled with geographic isolation (Knowles, 2010; Qu et al. , 2011). Based on Bayesian estimation, the time of divergence (0.68 Ma) between the populations in the Nanling Mts. and those of the east coincides with the last third glacial period in China in the Middle Pleistocene (Figure 4). The time may fall in the Naynayxungla Glacial period (0.5-0.7 Ma; Zheng, Xu, \& Shen, 2002; Zhou \& Li, 1998), Dagu Glacial period (0.5-0.6 Ma; Duan, Pu, \& Wu, 1980), Kunlun Glacial period (0.62-0.78 Ma; Zhao, Shi, \& Wang, 2011), or Poyang-Dagu Interglacial (Duan, Pu, \& Wu, 1980). Although the time for the glaciations is uncertain, primarily the third (last) glaciation drove the genetic divergence between populations in the Nanling Mts. and those to the east, and shaped the geographical patterns of genetic variation. The estimated divergence time of the best fit model in FSC2 is older, i.e. 1.60 Ma (Figure 5), which overlaps with the earliest known Quaternary glacial of the Xixiabangma Glacial period ca. 1.6 Ma (Wan et al., 2016), or the Sizishan Periglacial period (Duan, Pu, \& Wu, 1980), when the temperature was 10 lower than at present. The discrepancy between the results of Bayesian time estimation and FSC2 may be partially attributed to the wider time range under the log-uniform setting in FSC2. The secondary calibration used in BEAST is thought to generate smaller time estimates (Foster et al., 2017; Kong, 2017; Kong, Zhang, Hong, \& Barker, 2017). The climate during glacial periods tended to be dry and cool, which would favor the populations shifting to lower elevations with contracted distribution ranges. The glacial period in the Middle Pleistocene have been shown to drive spruce fir forests to lowlands in northern China (Liu, 1988). In our study, the geographical distribution of C. chuniana in southern China is also associated with the Pleistocene glacial cycles (Figure 4). The Dagu Glacial period primarily affected the population divergence between the east and west, whereas the Dagu-Lushan Interglacial period and Lushan Glacial period primarily affected population diversification. The dominant role for Pleistocene glacial cycles on the geographic distribution of populations is also apparent in ENM, where several isolated glacial refugia were identified during the LGM, although the climatic conditions may not be analogous to that of other glacial cycles.

\subsection{Secondary contact, demographic expansion and contemporary west-to-east migrations}

FSC2 analyses indicate a best-fit model of isolation followed by secondary contact and demographic expansion (Table 3, Figure 5). The estimated time of secondary contact from our analysis (0.10 Ma) coincides with the Lushan-Tali interglacial period in China (0.10-0.20 Ma) (Duan, $\mathrm{Pu}, \& \mathrm{Wu}, 1980$ ), when a continuous geographic distribution of $C$. chuniana along the mountain ranges in southern China was detected by ENM (Figure 2a). Although the Lushan-Tali interglacial period is younger than the LIG $\left(0.12^{\sim} 0.14 \mathrm{Ma}\right)$, it still lies within the interglacial period in China when temperature increased and was estimated to be even higher than the present (Duan, $\mathrm{Pu}, \& \mathrm{Wu}, 1980$; Zhu et al., 2004). This suggests that the secondary contact may 
occur during this warmer time. Moreover, it is thought that the East Asia summer monsoon intensified then due to increased temperature with more precipitation during the interglacial period (Liu et al. , 2018; Meng et al. , 2018; Wang et al., 1999; Wang et al., 2007; Wang et al., 2012), thus providing more suitable habitat, especially in considering that $C$. chuniana is adapted to mesic environments and most influenced by precipitation (Table S1). In the same model, demographic expansion in the Nanling Mts. was inferred with notably increased effective population size (Table 3, Figure 5), indicating high local population diversification (Figure 3). The Nanling Mts., which are composed of five distinct ridges, has a long history of STEBF in southern China (Fan et al. , 2018; Xu et al. , 2017). Its vegetation is characterized by highly varied elevational or longitudinal shifts (Shen et al. , 2019; Zhu et al. , 2017), which confers relatively stable ecological conditions to these mountains during glacial periods and has served as a buffer from climatic change. It had almost the same annual precipitation during the last glacial period as current (Tian \& Jiang, 2016). Therefore, complex physiography plus long-term stable ecological conditions in the Nanling Mts. across glacial cycles are thought to preserve population diversity, finally resulting in population size increase and demographic expansion. Similar cases have been documented in widespread species in subtropical China, such as Eurycorymbus cavaleriei, Loropetalum chinense andEomecon chionantha (Gong et al., 2016; Tian et al., 2018; Wang, Gao, Kang, Lowe, \& Huang, 2009). Most of the previous research is conducted using the traditional molecular markers and data analysis methods, with more intensive population sampling, compared with the current study. We consider population genomic approaches based on the next generation sequencing are more effective ways to detect the population dynamics, even for the species with relatively narrow distribution.

Additionally, FSC2 analysis indicated bidirectional migrations occurring after NL and ES divergence, with $M_{\text {NL-ES }}$ (2.14) higher than $M_{\text {ES-NL }}$ (0.33) (Table 3, Figure 5). The migrations in C. chuniana seem to proceed primarily from the Nanling Mts. to the east. Many examples of plant species in East Asia exhibit a similar distribution pattern and migration route, such as Tetrastigma hemsleyanum and Eomecon chionantha (Tian et al., 2018; Wang, 1992a; 1992b; Wang et al. , 2015). The question arises as to why contemporary migration direction is inferred from the Nanling Mts. towards the east, whereas the former diverged more recently than the latter. The Nanling Mts., with distinct phytogeography and long-term stable ecological condition, is thought to be one of the glacial refugia for C. chuniana. Populations of C. chuniana are present at relatively higher elevations in the Nanling Mts. than the eastern ones, which may facilitate the west-to-east migration from higher elevations to lower ones via closely adjacent stepping-stone areas across the mountain ranges.

\section{ACKNOWLEDGEMENTS}

This work was supported by the National Natural Science Foundation of China (31470312; 31470319; 31970231), Science and Technology Planning Project of Guangdong Province, China (2016A030303048). We thank Xiaolan Wang, Juan Zhou, Bo Li, Yemei Huang, and Zhong Zhang for help with sampling and field trips. We thank Zhixia Sun, Mark Ravinet, Joana Meier, Tongjian Liu, Huiqin Yi, and Haifei Yan for data analyses. Special thank goes to Prof. Qi Wang for providing fossil information.

\section{Author contributions}

W. G. and G. H. supervised and designed the research. WZ. L. conducted field investigation and sample collection. WZ. L., JG. X. and H. Z. carried out the lab work. WZ. L., HH. K., W. G., and PW. F. analyzed the genomic data. WZ. L., PW. F. and W. G. discussed the results and wrote the manuscript. All authors read and agree with the manuscript.

\section{Data Accessibility statement}

The data have been deposited in Figshare (DOI: XXX).

\section{REFERENCES}

Akaike, H. (1974). A new look at the statistical model identification.IEEE Transactions on Automatic Control, 19 (6), 716-723. doi:10.1109/TAC.1974.1100705 
Aldworth, S. J. (1998). Trees and Shrubs of the Campus of Iowa State University: A Walking Tour of One Hundred Species : Iowa State University, Department of Botany.

Alexandros, S. (2014). RAxML version 8: a tool for phylogenetic analysis and post-analysis of large phylogenies. Bioinformatics, 30 (9), 1312-1313. doi:10.1093/bioinformatics/btu033

Andrews, K. R., Good, J. M., Miller, M. R., Luikart, G., \& Hohenlohe, P. A. (2016). Harnessing the power of RADseq for ecological and evolutionary genomics. Nature Reviews Genetics, 17 (2), 81-92. doi:10.1038/nrg.2015.28

Azani, N., Babineau, M., Bailey, C. D., Banks, H., Barbosa, A. R., Pinto, R. B., Zimmerman, E. (2017). A new subfamily classification of the Leguminosae based on a taxonomically comprehensive phylogeny. Taxon, 66 (1), 44-77. doi:10.12705/661.3

Bouckaert, R., Heled, J., Kuhnert, D., Vaughan, T., Wu, C. H., Xie, D., Drummond, A. J. (2014). BEAST 2: a software platform for Bayesian evolutionary analysis. Plos Computational Biology, 10 (4), e1003537. doi:10.1371/journal.pcbi.1003537

Catchen, J., Hohenlohe, P. A., Bassham, S., Amores, A., \& Cresko, W. A. (2013). Stacks: an analysis tool set for population genomics.Molecular Ecology, 22 (11), 3124-3140. doi:10.1111/mec.12354

Chen, D., Zhang, D., Larsen, S. S., \& Vincent M. A. (2010).Cercis . In Flora of China (Vol. 10, pp. 5-6): Science Press: Beijing, China.

Chen, S. C., Zhang, L., Zeng, J., Shi, F., Yang, H., Mao, Y. R., \& Fu, C. X. (2012). Geographic variation of chloroplast DNA inPlatycarya strobilacea (Juglandaceae). Journal of Systematics and Evolution, 50 (4), 374-385. doi:10.1111/j.1759-6831.2012.00210.x

Chen, W., Hou, L., Zhang, Z. Y., Pang, X. M., \& Li, Y. Y. (2017). Genetic diversity, population structure, and linkage disequilibrium of a core collection of Ziziphus jujuba assessed with genome-wide SNPs developed by genotyping-by-sequencing and SSR markers. Frontiers in Plant Science, 8 , 575. doi:10.3389/fpls.2017.00575

Chen, Y. S., Deng, T., Zhou, Z., \& Sun, H. (2018). Is the East Asian flora ancient or not? National Science Review, 5 (6), 920-932. doi:10.1093/nsr/nwx156

Chen, Z., \& Mao, F. (1999). Plant composition and ecological characteristics of Cercis yunnanensis Coppice. Yunnan Forestryence 83 Technology . (1), 01.

Colin, H., \& Ruth, E. (2006). Island radiation on a continental scale: Exceptional rates of plant diversification after uplift of the Andes.Proceedings of the National Academy of Sciences of the United States of America, 103 (27), 10334-10339. doi:10.1073/pnas.0601928103

Collins, W., Bitz, C., Blackmon, M., Bonan, G., Bretherton, C., Carton, J., Smith, R. (2006). The community climate system Model Version 3 (CCSM3). Journal of Climate, 19 (11), 2122-2143. doi:10.1175/JCLI3761.1

Dai, C. Y., Zhao, N., Wang, W. J., Lin, C. T., Gao, B., Yang, X. J., Lei, F. M. (2011). Profound climatic effects on two East Asian black-throated tits (Ave: Aegithalidae), revealed by ecological niche models and phylogeographic analysis. Plos One, 6 (12). e29359 . doi:10.1371/journal.pone.0029329

Davey, J. W., Hohenlohe, P. A., Etter, P. D., Boone, J. Q., Catchen, J. M., \& Blaxter, M. L. (2011). Genome-wide genetic marker discovery and genotyping using next-generation sequencing. Nature Reviews Genetics, 12 (7), 499-510. doi:10.1038/nrg3012

Doyle, J., \& Doyle, J. (1986). A rapid DNA isolation procedure from small quantities of fresh leaf tissues. Phytochem Bull, 19 (1), 11-15. 
Duan, W., Pu, Q., \& Wu, X. (1980). Climatic variations in China during the quaternary. GeoJournal, 4, 515-524. doi:10.1007/BF00214217

Excoffier, L., Dupanloup, I., Huerta-Sanchez, E., Sousa, V. C., \& Foll, M. (2013). Robust demographic inference from genomic and SNP data.Plos Genetics, 9 (10), e1003905. doi:10.1371/journal.pgen.1003905

Excoffier, L., \& Lischer, H. E. L. (2010). Arlequin suite ver 3.5: a new series of programs to perform population genetics analyses under Linux and Windows. Molecular Ecology Resources, 10 (3), 564-567. doi:10.1111/j.1755-0998.2010.02847.x

Excoffier, L., Smouse, P. E., \& Quattro, J. M. (1992). Analysis of molecular variance inferred from metric distances among DNA haplotypes: application to human mitochondrial DNA restriction data. Genetics, 131 (2), 479-491.

Fan, D. M., Huang, J. H., Hu, H. L., Sun, Z. X., Cheng, S. M., Kou, Y. X., \& Zhang, Z. Y. (2018). Evolutionary hotspots of seed plants in subtropical China: A comparison with species diversity hotspots of woody seed plants. Frontiers in Genetics, 9 , 333. doi:10.3389/fgene.2018.00333

Fick, S. E., \& Hijmans, R. J. (2017). WorldClim 2: new 1-km spatial resolution climate surfaces for global land areas. International Journal of Climatology, 37 (12), 4302-4315. doi:10.1002/joc.5086

Fielding, A. H., \& Bell, J. F. (1997). A review of methods for the assessment of prediction errors in conservation presence/absence models.Environmental Conservation, 24 (1), 38-49. doi:10.1017/s0376892997000088

Foster, C. S. P., Sauquet, H., Van der Merwe, M., McPherson, H., Rossetto, M., \& Ho, S. Y. W. (2017). Evaluating the impact of genomic data and priors on Bayesian estimates of the angiosperm evolutionary timescale. Systematic Biology, 66 (3), 338-351. doi:10.1093/sysbio/syw086

Fritsch, P. W., \& Cruz, B. C. (2012). Phylogeny of Cercis based on DNA sequences of nuclear ITS and four plastid regions: Implications for transatlantic historical biogeography. Molecular Phylogenetics and Evolution, 62 (3), 816-825. doi:10.1016/j.ympev.2011.11.016

Fritsch, P. W., Nowell, C. F., Leatherman, L. S. T., Gong, W., Cruz, B. C., Burge, D. O., \& Delgado-Salinas, A. (2018). Leaf adaptations and species boundaries in North American Cercis: implications for the evolution of dry floras. American Journal of Botany, 105 (9), 1577-1594. doi:10.1002/ajb2.1155

Gong, W., Chen, C., Dobes, C., Fu, C. X., \& Koch, M. A. (2008). Phylogeography of a living fossil: Pleistocene glaciations forcedGinkgo biloba L. (Ginkgoaceae) into two refuge areas in China with limited subsequent postglacial expansion. Molecular Phylogenetics and Evolution, 48 (3), 1094-1105. doi:10.1016/j.ympev.2008.05.003

Gong, W., Liu, W. Z., Gu, L., Kaneko, S., Koch, M. A., \& Zhang, D. X. (2016). From glacial refugia to wide distribution range: demographic expansion of Loropetalum chinense (Hamamelidaceae) in Chinese subtropical evergreen broadleaved forest. Organisms Diversity \& Evolution, 16 (1), 23-38. doi:10.1007/s13127-015$0252-4$

Ha, Y. H., Kim, C., Choi, K., \& Kim, J. H. (2018). Molecular phylogeny and dating of Forsythieae (Oleaceae) provide insight into the Miocene history of Eurasian temperate shrubs. Frontiers in Plant Science, 9 , 99. doi:10.3389/fpls.2018.00099

Harrington, S. M., Hollingsworth, B. D., Higham, T. E., \& Reeder, T. W. (2018). Pleistocene climatic fluctuations drive isolation and secondary contact in the red diamond rattlesnake (Crotalus ruber) in Baja California. Journal of Biogeography, 45 (1), 64-75. doi:10.1111/jbi.13114

Heffelfinger, C., Fragoso, C. A., Moreno, M. A., Overton, J. D., Mottinger, J. P., Zhao, H. Y., Dellaporta, S. L. (2014). Flexible and scalable genotyping-by-sequencing strategies for population studies.BMC Genomics, 15 (1), 979. doi:10.1186/1471-2164-15-979 
Hewitt, G. M. (2004). Genetic consequences of climatic oscillations in the Quaternary. Philosophical Transactions of the Royal Society of London Series B-Biological Sciences, 359 (1442), 183-195. doi:10.1098/rstb.2003.1388

Hijmans, R. J., Cameron, S. E., Parra, J. L., Jones, P. G., \& Jarvis, A. (2005). Very high resolution interpolated climate surfaces for global land areas. International Journal of Climatology, 25 (15), 19651978. doi:10.1002/joc. 1276

Hohmann, N., Wolf, E. M., Rigault, P., Zhou, W. B., Kiefer, M., Zhao, Y. P., Koch, M. A. (2018). Ginkgo biloba 's footprint of dynamic Pleistocene history dates back only 390,000 years ago. BMC Genomics, 19 (1), 299. doi:10.1186/s12864-018-4673-2

Hou, H. Y. (1983). Vegetation of China with reference to its geographical distribution. Annals of the Missouri Botanical Garden, 70 (3), 509-549. doi:10.2307/2992085

Hou, B. W., Luo, J., Zhang, Y. S., Niu, Z. T., Xue, Q. Y., \& Ding, X. Y. (2017). Iteration expansion and regional evolution: phylogeography ofDendrobium officinale and four related taxa in southern China.Scientific Reports, 7 (1), 43525. doi:10.1038/srep43525

Hughes, C. E. (2017). Are there many different routes to becoming a global biodiversity hotspot? Proceedings of the National Academy of Sciences of the United States of America, 114 (17), 4275-4277. doi:10.1073/pnas.1703798114

Hughes, C. E., \& Atchison, G. W. (2015). The ubiquity of alpine plant radiations: from the Andes to the Hengduan Mountains. New Phytologist, 207 (2), 275-282. doi:10.1111/nph.13230

Ilut, D. C., Nydam, M. L., \& Hare, M. P. (2014). Defining loci in restriction-based reduced representation genomic data from nonmodel species: sources of bias and diagnostics for optimal clustering. Biomed Research International . 2014 . doi:10.1155/2014/675158

Isely, D. (1975). Leguminosae of the United States. II. Subfamily Caesalpinioideae. Memoirs of the New York Botanical Garden .

Jiang, X. L., Xu, G. B., \& Deng, M. (2019). Spatial genetic patterns and distribution dynamics of the rare Oak Quercus chungii : Implications for biodiversity conservation in Southeast China.Forests, 10 (9), 821. doi:10.3390/f10090821

Kadereit, J. W. (2017). The role of in situ species diversification for the evolution of high vascular plant species diversity in the European Alps-A review and interpretation of phylogenetic studies of the endemic flora of the Alps. Perspectives in Plant Ecology Evolution and Systematics, 26 , 28-38. doi:10.1016/j.ppees.2017.03.002

Knowles, L. L. (2001). Did the Pleistocene glaciations promote divergence? Tests of explicit refugial models in montane grasshoppers. Molecular Ecology, 10 (3), 691-701. doi:10.1046/j.1365-294x.2001.01206.x

Kong, H. H., Condamine, F. L., Harris, A. J., Chen, J. L., Pan, B., Moller, M., Kang, M. (2017). Both temperature fluctuations and East Asian monsoons have driven plant diversification in the karst ecosystems from southern China. Molecular Ecology, 26 (22), 6414-6429. doi:10.1111/mec.14367

Kong, H. H., Zhang, Y., Hong, Y., \& Barker, M. S. (2017). Multilocus phylogenetic reconstruction informing polyploid relationships of Aconitum subgenus Lycoctonum (Ranunculaceae) in China.Plant Systematics and Evolution, 303 (6), 727-744. doi:10.1007/s00606-017-1406-y

Lefort, V., Longueville, J. E., \& Gascuel, O. (2017). SMS: smart model selection in PhyML. Molecular Biology and Evolution, 34 (9), 2422-2424. doi:10.1093/molbev/msx149

Li, H., \& Durbin, R. (2009). Fast and accurate short read alignment with Burrows-Wheeler transform. Bioinformatics, 25 (14), 1754-1760. doi:10.1093/bioinformatics/btp324 
Li, H., Handsaker, B., Wysoker, A., Fennell, T., Ruan, J., Homer, N., Durbin, R. (2009). Genome project data processing S: The Sequence Alignment/Map format and SAMtools. Bioinformatics , 25 (16), 20782079. doi:10.1093/bioinformatics/btp352

Li, H., Kong, L., Wang, K., Zhang, S., Motokawa, M., Wu, Y., Li, Y. (2019). Molecular phylogeographic analyses and species delimitations reveal that Leopoldamys edwardsi (Rodentia: Muridae) is a species complex. Integrative Zoology, 14 (5), 494-505. doi:10.1111/1749-4877.12378

Li, J., Wen, S., Zhang, Q., Wang, F., Zheng, B., \& Li, B. (1979). A discussion on the period,amplitude and type of the uplift of the Qinghai-Xizang plateau. Scientia Sinica, 22 , 1314-1328.

Liu, K. (1988) Quaternary history of the temperate forests of China.Quaternary Science Reviews, 7 (1), 1-20. doi:10.1016/0277-3791(88)90089-3

Li, X. H., Shao, J. W., Lu, C., Zhang, X. P., \& Qiu, Y. X. (2012). Chloroplast phylogeography of a temperate tree Pteroceltis tatarinowii (Ulmaceae) in China. Journal of Systematics and Evolution, 50 (4), 325-333. doi:10.1111/j.1759-6831.2012.00203.x

Liu, H. T., Wang, W. J., Song, G., Qu, Y. H., Li, S. H., Fjeldsa, J., \& Lei, F. M. (2012). Interpreting the process behind endemism in China by integrating the phylogeography and ecological niche models of theStachyridopsis ruficeps . Plos One, 7 (10), e46761. doi:10.1371/journal.pone.0046761

Liu, J., Moller, M., Provan, J., Gao, L. M., Poudel, R. C., \& Li, D. Z. (2013). Geological and ecological factors drive cryptic speciation of yews in a biodiversity hotspot. New Phytologist, 199 (4), 1093-1108. doi:10.1111/nph.12336

Liu, J. S., Algeo, T. J., Yang, H., Pan, J. J., Tang, C. Y., Huang, J. H., \& Xie, S. C. (2018). Changes in vegetation type on the Chinese Loess Plateau since 75 ka related to East Asian Summer Monsoon variation. Palaeogeography Palaeoclimatology Palaeoecology, 510 , 124-139. doi:10.1016/j.palaeo.2018.02.030

Liu Z.Z. (1984) The origin and morphological characteristics of the Wuyi Mountains, Fujian Province. Journal of Nanjing University Natural Science , 3 , 567-578.

Lopez-Pujol, J., Zhang, F. M., Sun, H. Q., Ying, T. S., \& Ge, S. (2011). Centres of plant endemism in China: places for survival or for speciation? Journal of Biogeography, 38 (7), 1267-1280. doi:10.1111/j.13652699.2011.02504.x

Lu, L. M., Mao, L. F., Yang, T., Ye, J. F., Liu, B., Li, H. L., Chen, Z. D. (2018). Evolutionary history of the angiosperm flora of China.Nature, 554 (7691), 234 -238. doi:10.1038/nature25485

Matuszak, S., Muellner-Riehl, A. N., Sun, H., \& Favre, A. (2016). Dispersal routes between biodiversity hotspots in Asia: the case of the mountain genus Tripterospermum (Gentianinae, Gentianaceae) and its close relatives. Journal of Biogeography, 43 (3), 580-590. doi:10.1111/jbi.12617

Melo, A. T. O., Bartaula, R., \& Hale, I. (2016). GBS-SNP-CROP: a reference-optional pipeline for SNP discovery and plant germplasm characterization using variable length, paired-end genotyping-by-sequencing data. BMC Bioinformatics, 17 (1), 29. doi:10.1186/s12859-016-0879-y

Meng, X. Q., Liu, L. W., Wang, X. C. T., Balsam, W., Chen, J., \& Ji, J. F. (2018). Mineralogical evidence of reduced East Asian summer monsoon rainfall on the Chinese loess plateau during the early Pleistocene interglacials. Earth and Planetary Science Letters, 486 , 61-69. doi:10.1016/j.epsl.2017.12.048

Mesquita, C. P. B. d., Tillmann, L. S., Bernard, C. D., Rosemond, K. C., \& Suding, K. N. (2018). Topographic heterogeneity explains patterns of vegetation response to climate change (1972-2008) across a mountain landscape, Niwot Ridge, Colorado. Arctic Antarctic and Alpine Research, 50 (1), e1504492. doi: $10.1080 / 15230430.2018 .1504492$

Metcalf, F. P. (1940). Eight new species of Leguminosae from Southeastern China. Lingnan Science Journal , $19,549-563$. 
Metzker, M. L. (2010). Applications of next-generation sequencing. Sequencing technologies-the next generation. Nature Reviews Genetics, 11 (1), 31-46. doi:10.1038/nrg2626

Miller, M. A., Terri, S., Pickett, B. E., Sherry, H., Klem, E. B., Scheuermann, R. H., O'Leary, M. A. (2015). A RESTful API for Access to Phylogenetic Tools via the CIPRES Science Gateway. Evolutionary Bioinformatics, 11 (11), 43-48. doi:10.4137/EBO.S21501

Muellner-Riehl, A. N. (2019). Mountains as Evolutionary Arenas: Patterns, Emerging Approaches, Paradigm Shifts, and Their Implications for Plant Phylogeographic Research in the Tibeto-Himalayan Region.Frontiers in Plant Science, 10 , 195. doi:10.3389/fpls.2019.00195

Nevado, B., Contreras-Ortiz, N., Hughes, C., \& Filatov, D. A. (2018). Pleistocene glacial cycles drive isolation, gene flow and speciation in the high-elevation Andes. New Phytologist, 219 (2), 779-793. doi:10.1111/nph.15243

Niu, S. Z., Song, Q. F., Koiwa, H., Qiao, D. H., Zhao, D. G., Chen, Z. W., Wen, X. P. (2019). Genetic diversity, linkage disequilibrium, and population structure analysis of the tea plant (Camellia sinensis) from an origin center, Guizhou plateau, using genome-wide SNPs developed by genotyping-by-sequencing. BMC Plant Biology, 19 (1), 328. doi:10.1186/s12870-019-1917-5

Oyama, K., Ramirez-Toro, W., Penaloza-Ramirez, J. M., Pedraza, A. E. P., Torres-Miranda, C. A., RuizSanchez, E., \& Gonzalez-Rodriguez, A. (2018). High genetic diversity and connectivity among populations ofQuercus candicans, Quercus crassifolia, and Quercus castanea in a heterogeneous landscape in Mexico. Tropical Conservation Science, 11 , 1940082918766195. doi:10.1177/1940082918766195

Pearson, R. G., Raxworthy, C. J., Nakamura, M., \& Peterson, A. T. (2007). Predicting species distributions from small numbers of occurrence records: a test case using cryptic geckos in Madagascar. Journal of Biogeography, 34 (1), 102-117. doi:10.1111/j.1365-2699.2006.01594.x

Petr, D., Adam, A., Goncalo, A., Albers, C. A., Eric, B., Depristo, M. A., Sherry, S. T. (2011). The variant call format and VCFtools.Bioinformatics, 27 (15), 2156-2158. doi:10.1093/bioinformatics/btr330

Phillips, S. J., Anderson, R. P., \& Schapire, R. E. (2006). Maximum entropy modeling of species geographic distributions. Ecological Modelling, 190 (3-4), 231-259. doi:10.1016/j.ecolmodel.2005.03.026

Qiu, B. W., Zeng, C. Y., Chen, C. C., Zhang, C. G., \& Zhong, M. (2013). Vegetation distribution pattern along altitudinal gradient in subtropical mountainous and hilly river basin, China. Journal of Geographical Sciences, 23 (2), 247-257. doi:10.1007/s11442-013-1007-9

Qiu, Y. X., Guan, B. C., Fu, C. X., \& Comes, H. (2009). Did glacials and/or interglacials promote allopatric incipient speciation in East Asian temperate plants? Phylogeographic and coalescent analyses on refugial isolation and divergence in Dysosma versipellis . Molecular Phylogenetics and Evolution, 51, 281-293. doi:10.1016/j.ympev.2009.01.016

Qiu, Y. X., Fu, C. X., \& Comes, H. P. (2011). Plant molecular phylogeography in China and adjacent regions: Tracing the genetic imprints of Quaternary climate and environmental change in the world's most diverse temperate flora. Molecular Phylogenetics and Evolution, 59 (1), 225-244. doi:10.1016/j.ympev.2011.01.012

Qu, Y. H., Luo, X., Zhang, R. Y., Song, G., Zou, F. S., \& Lei, F. M. (2011). Lineage diversification and historical demography of a montane bird Garrulax elliotii - implications for the Pleistocene evolutionary history of the eastern Himalayas. BMC Evolutionary Biology, 11 (1), 174. doi:10.1111/j.1365-294X.2008.03998.x

Raj, A., Stephens, M., \& Pritchard, J. K. (2014). fastSTRUCTURE: variational inference of population structure in large SNP data sets.Genetics, 197 (2), 573- 589. doi:10.1534/genetics.114.164350

Rambaut, A. (2014). FigTree 1.4.3 software. Institute of Evolutionary Biology, Univ. Edinburgh . Retrieved from http://tree.bio.ed.ac.uk/software/figtree/ 
Rambaut, A., Suchard, M. A., Xie, D., \& Drummond, A. J. (2014). Tracer v1. 6. Retrieved from http://beast.bio.ed.ac.uk/Tracer

Ray, N., \& Adams, J. M. (2001). A GIS-based vegetation map of the world at the last glacial maximum (25,000-15,000 BP). Internet Archaeology, 11 . doi:10.11141/ia.11.2

Ronquist, F. (1997). Dispersal-vicariance analysis: a new approach to the quantification of historical biogeography. Systematic Biology , 46 (1), 195-203. doi:10.2307/2413643

Scheben, A., Batley, J., \& Edwards, D. (2017). Genotyping-by-sequencing approaches to characterize crop genomes: choosing the right tool for the right application. Plant Biotechnology Journal, 15 (2), 149-161. doi:10.1111/pbi.12645

Shen, Y. F., Cheng, Y. L., Li, K. Q., \& Li, H. G. (2019). Integrating phylogeographic analysis and geospatial methods to infer historical dispersal routes and glacial refugia of Liriodendron chinense.Forests, 10 (7), 565. doi:10.3390/f10070565

Shi, Y. F., Cui, Z. J., \& Su, Z. (2006). The Quaternary glaciations and environmental variations in China . Shijiazhuang, China: Hebei Science and Technology Press.

Shi, Y. F., Li, J. J., \& Li, B. Y. (1998). Uplift and environmental changes of Qinghai-Tibetan Plateau in the Late Cenozoic. Guangzhou, China:Guangdong Science and Technology Press .

Simpson, G. (1964). Species density of North American recent mammals.Systematic Zoology, 13 (2), 57-73. doi:10.2307/2411825

Soberon, J., \& Peterson, A. (2005). Interpretation of models of fundamental ecological niches and species' distributional areas.Biodiversity Informatics, 2 (0). doi:10.17161/bi.v2i0.4

Svenning, J. C., Normand, S., \& Skov, F. (2009). Plio-Pleistocene climate change and geographic heterogeneity in plant diversity-environment relationships. Ecography, 32 (1), 13-21. doi:10.1111/j.16000587.2008.05732.x

Tian, S., Kou, Y. X., Zhang, Z. R., Yuan, L., Li, D. R., Lopez-Pujol, J., Zhang, Z. Y. (2018). Phylogeography of Eomecon chionantha in subtropical China: the dual roles of the Nanling Mountains as a glacial refugium and a dispersal corridor. BMC Evolutionary Biology, 18 (1), 20. doi:10.1186/s12862-017-1093-x

Tian, S., Lei, S. Q., Hu, W., Deng, L. L., Li, B., Meng, Q. L., Zhang, Z. Y. (2015). Repeated range expansions and inter-/postglacial recolonization routes of Sargentodoxa cuneata (Oliv.) Rehd. et Wils. (Lardizabalaceae) in subtropical China revealed by chloroplast phylogeography. Molecular Phylogenetics and Evolution, 85 , 238-246. doi:10.1016/j.ympev.2015.02.016

Tian, X. Y., Ye, J. W., Wang, T. M., Bao, L., \& Wang, H. F. (2020). Different processes shape the patterns of divergence in the nuclear and chloroplast genomes of a relict tree species in East Asia. Ecology and Evolution, 10 (10), 4331-4342. doi:10.1002/ece3.6200

Tian, Z. P., \& Jiang, D. B. (2016). Revisiting last glacial maximum climate over China and East Asian monsoon using PMIP3 simulations.Palaeogeography Palaeoclimatology Palaeoecology, 453 , 115-126. doi:10.1016/j.palaeo.2016.04.020

Wan, D. S., Feng, J. J., Jiang, D. C., Mao, K. S., Duan, Y. W., Miehe, G., \& Opgenoorth, L. (2016). The Quaternary evolutionary history, potential distribution dynamics, and conservation implications for a Qinghai-Tibet Plateau endemic herbaceous perennial, Anisodus tanguticus (Solanaceae). Ecology and Evolution, 6 (7), 1977-1995. doi:10.1002/ece3.2019

Wang, H., Qiong, L., Sun, K., Lu, F., Wang, Y. G., Song, Z. P., Zhang, W. J. (2010). Phylogeographic structure of Hippophae tibetana(Elaeagnaceae) highlights the highest microrefugia and the rapid uplift of the Qinghai-Tibetan Plateau. Molecular Ecology, 19 (14), 2964-2979. doi:10.1111/j.1365-294x.2010.04729.x 
Wang, J., Gao, P. X., Kang, M., Lowe, A. J., \& Huang, H. W. (2009). Refugia within refugia: the case study of a canopy tree (Eurycorymbus cavaleriei) in subtropical China. Journal of Biogeography, 36 (11), 2156-2164. doi:10.1111/j.1365-2699.2009.02165.x

Wang, L., Sarnthein, M., Erlenkeuser, H., Grimalt, J., Grootes, P., Heilig, S., Pflaumann, U. (1999). East Asian monsoon climate during the Late Pleistocene: High-resolution sediment records from the South China Sea. Marine Geology, 156 (1-4), 245-284. doi:10.1016/S0025-3227(98)00182-0

Wang, R. J., Jian, Z. M., Xiao, W. S., Tian, J., Li, J. R., Chen, R. H., Chen, J. F. (2007). Quaternary biogenic opal records in the South China Sea: Linkages to East Asian monsoon, global ice volume and orbital forcing. Science in China Series D-Earth Sciences, 50 (5), 710-724. doi:10.1007/s11430-007-0041-9

Wang, W. T. (1992a). On some distribution patterns and some migration routes found in the eastern Asiatic region. Acta Phytotaxonomica Sinica, 30 (1), 1-24.

Wang, W. T. (1992b). On some distribution patterns and some migration routes found in the eastern Asiatic region (Cont.). Acta Phytotaxonomica Sinica (China) , 30(2), 97-117.

Wang, Y. H., Jiang, W. M., Comes, H. P., Hu, F. S., Qiu, Y. X., \& Fu, C. X. (2015). Molecular phylogeography and ecological niche modelling of a widespread herbaceous climber, Tetrastigma hemsleyanum(Vitaceae): insights into Plio-Pleistocene range dynamics of evergreen forest in subtropical China. New Phytologist, 206 (2), 852-867. doi:10.1111/nph.13261

Wang, Z. H., Fang, J. Y., Tang, Z. Y., \& Shi, L. (2012). Geographical patterns in the beta diversity of China's woody plants: the influence of space, environment and range size. Ecography, 35 (12), 1092-1102. doi:10.1111/j.1600-0587.2012.06988.x

Weir, B. (1996). Genetic Data Analysis. Methods for Discrete Population Genetic Data . Sunderland, Massachusetts, USA: Sinauer Associates, Inc. Publishers.

Weir, B., \& Cockerham, C. (1984). Estimating F-statistics for the analysis of population structure. Evolution, 38 , 1358-1370. doi:10.1111/j.1558-5646.1984.tb05657.x

Wunderlin, R.P., Larsen, K. \& Larsen, S.S. (1981). Tribe 3. Cercideae Bronn. In Polhill, R.M. \& Raven, P.H.(Eds.), Advances in Legume Systematics, Part 1 . (pp. 107-116). Surrey, UK: Kew: Royal Botanical Garden.

Xing, Y. W., \& Ree, R. H. (2017). Uplift-driven diversification in the Hengduan Mountains, a temperate biodiversity hotspot. Proceedings of the National Academy of Sciences of the United States of America, 114 (17), E3444-E3451. doi:10.1073/pnas.1616063114

Xiong, L. F., Wu, S. C., \& Zhang, S. H. (2019). Mechanical behavior of a granite from Wuyi mountain: Insights from Strain-Based Approaches.Rock Mechanics and Rock Engineering, 52 (3), 719-736. doi:10.1007/s00603-018-1617-8

Xu, Y., Shen, Z. H., Ying, L. X., Wang, Z. H., Huang, J. H., Zang, R. G., \& Jiang, Y. X. (2017). Hotspot analyses indicate significant conservation gaps for evergreen broadleaved woody plants in China.Scientific Reports, 7 (1), 1-10. doi:10.1038/s41598-017-02098-0

Yan, F., Zhou, W., Zhao, H., Yuan, Z., Wang, Y., Jiang, K., Jin, J., Murphy, R.W., Che, J. \& Zhang, Y. (2013). Geological events play a larger role than Pleistocene climatic fluctuations in driving the genetic structure of Quasipaa boulengeri (Anura: Dicroglossidae).Molecular Ecology , 22 (4), 1120-1133. $10.1111 /$ mec. 12153

Yang, A. H., Dick, C. W., Yao, X. H., \& Huang, H. W. (2016). Impacts of biogeographic history and marginal population genetics on species range limits: a case study of Liriodendron chinense. Scientific Reports, 6 (1), 25632. doi:10.1038/srep25632 
Yang, A. H., Zhong, Y. D., Liu, S. J., Liu, L. P., Liu, T. Y., Li, Y. Q., \& Yu, F. X. (2019). New insight into the phylogeographic pattern of Liriodendron chinense (Magnoliaceae) revealed by chloroplast DNA: east-west lineage split and genetic mixture within western subtropical China. Peerj, 7, e6355. doi:10.7717/peerj.6355

Ying, J. (2001). Species diversity and distribution pattern of seed plants in China. Chinese Biodiversity., 9 (4), 393-398.

Yu, Y., Harris, A. J., Blair, C., \& He, X. J. (2015). RASP (Reconstruct Ancestral State in Phylogenies): A tool for historical biogeography.Molecular Phylogenetics and Evolution, 87, 46-49. doi:10.1016/j.ympev.2015.03.008

Zhao, J. D., Shi, Y. F., \& Wang J.. (2011). Comparison between Quaternary Glaciations in China and the Marine Oxygen Isotope Stage (MIS):An Improved Schema. Acta Geographica Sinica , 66 (7), 867-884.

Zheng, B., Xu, Q., \& Shen, Y. (2002). The relationship between climate change and Quaternary glacial cycles on the Qinghai-Tibetan Plateau: review and speculation. Quaternary International , 97 , 93-101. doi:10.1016/s1040-6182(02)00054-x

Zheng, X., Levine, D., Shen, J., Gogarten, S., Laurie, C., \& Weir, B. (2012). A high-performance computing toolset for relatedness and principal component analysis of SNP data. Bioinformatics (Oxford, England), 28 (24), 3326-3328. doi:10.1093/bioinformatics/bts606

Zhou, S., \& Li, J. (1998). The sequence of Quaternary glaciation in the Bayan Har Mountains. Quaternary International , 45 , 135-142. doi:10.1016/s1040-6182(97)00011-6

Zhu, Q., Liao, B. Y., Li, P., Li, J. C., Deng, X. M., Hu, X. S., \& Chen, X. Y. (2017). Phylogeographic pattern suggests a general northeastward dispersal in the distribution of Machilus pauhoi in South China. Plos One, 12 (9), e0184456. doi:10.1371/journal.pone.0184456

Zhu, R., Liu, Q., \& Jackson, M. (2004). Paleoenvironmental significance of the magnetic fabrics in Chinese loess-paleosols since the last interglacial (<130 ka). Earth and Planetary Science Letters, 221 (1-4), 55-69. doi:10.1016/S0012-821X(04)00103-7

\section{TABLES AND FIGURES}

TABLE 1 Accession information and genetic diversity parameters of observed heterozygosity (Ho ) and expected heterozygosity $(\mathrm{He})$ for the $11 \mathrm{C}$. chuniana populations.

\begin{tabular}{|c|c|c|c|c|c|c|c|c|}
\hline No. & Population & Location & $\begin{array}{l}\text { Mountain } \\
\text { range }\end{array}$ & $\mathrm{N}$ & Latitude & Longitude & $\begin{array}{l}\text { Elevation } \\
\text { range }(\mathbf{m})\end{array}$ & $\mathrm{He} / \mathrm{Ho}$ \\
\hline 1 & WYS1 & $\begin{array}{l}\text { Tonglingshan, } \\
\text { Wen- } \\
\text { zhou, } \\
\text { Zhejiang }\end{array}$ & $\begin{array}{l}\text { Eastern } \\
\text { Wuyi } \\
\text { Mts. }\end{array}$ & 8 & $27.82^{\mathrm{O}} \mathrm{N}$ & $119.85^{\mathrm{O}} \mathrm{E}$ & $264-727$ & $0.32 / 0$ \\
\hline 2 & WYS2 & $\begin{array}{l}\text { Wuyi } \\
\text { Mts., } \\
\text { Nan- } \\
\text { ping, } \\
\text { Fujian }\end{array}$ & $\begin{array}{l}\text { Western } \\
\text { Wuyi } \\
\text { Mts. }\end{array}$ & 9 & $27.94^{\mathrm{o}} \mathrm{N}$ & $117.77^{\circ} \mathrm{E}$ & $460-712$ & $0.34 / 0$ \\
\hline 3 & LXS1 & $\begin{array}{l}\text { Jinggangshan, } \\
\text { Ji'an, } \\
\text { Jiangxi }\end{array}$ & $\begin{array}{l}\text { Southern } \\
\text { Luoxiao } \\
\text { Mts. }\end{array}$ & 9 & $26.78^{\mathrm{o}} \mathrm{N}$ & $113.90^{\circ} \mathrm{E}$ & 264-509 & $0.32 / 0$ \\
\hline 4 & LXS2 & $\begin{array}{l}\text { Wuzhifeng, } \\
\text { Ganzhou, } \\
\text { Jiangxi }\end{array}$ & $\begin{array}{l}\text { Southern } \\
\text { Luoxiao } \\
\text { Mts. }\end{array}$ & 14 & $26.00^{\mathrm{O}} \mathrm{N}$ & $114.15^{\mathrm{o}} \mathrm{E}$ & $369-722$ & $0.31 / 0$ \\
\hline
\end{tabular}




\begin{tabular}{|c|c|c|c|c|c|c|c|c|}
\hline No. & Population & Location & $\begin{array}{l}\text { Mountain } \\
\text { range }\end{array}$ & $\mathrm{N}$ & Latitude & Longitude & $\begin{array}{l}\text { Elevation } \\
\text { range }(\mathbf{m})\end{array}$ & $\mathrm{He} / \mathrm{Ho}$ \\
\hline 5 & NLE1 & $\begin{array}{l}\text { Mangshan } \\
\text { Nature } \\
\text { Reserve, } \\
\text { Chen- } \\
\text { zhou, } \\
\text { Hunan }\end{array}$ & $\begin{array}{l}\text { Eastern } \\
\text { Nanling } \\
\text { Mts. }\end{array}$ & 12 & $24.98^{\mathrm{O}} \mathrm{N}$ & $112.89^{\circ} \mathrm{E}$ & 716 & $0.32 / 0$ \\
\hline 6 & NLE2 & $\begin{array}{l}\text { Dadongshan } \\
\text { Nature } \\
\text { Reserve, } \\
\text { Qingyuan, } \\
\text { Guangdong }\end{array}$ & $\begin{array}{l}\text { Eastern } \\
\text { Nanling } \\
\text { Mts. }\end{array}$ & 10 & $24.92^{\mathrm{O}} \mathrm{N}$ & $112.72^{\mathrm{O}} \mathrm{E}$ & 774 & $0.32 / 0$ \\
\hline 7 & NLW1 & $\begin{array}{l}\text { Yindianshan } \\
\text { Nature } \\
\text { Reserve, } \\
\text { Guilin, } \\
\text { Guangxi }\end{array}$ & $\begin{array}{l}\text { Western } \\
\text { Nanling } \\
\text { Mts. }\end{array}$ & 11 & $24.91^{\mathrm{O}} \mathrm{N}$ & $110.96^{\mathrm{o}} \mathrm{E}$ & 700 & $0.33 / 0$. \\
\hline 8 & NLW2 & $\begin{array}{l}\text { Tianpingshan, } \\
\text { Huap- } \\
\text { ingshan } \\
\text { Nature } \\
\text { Reserve, } \\
\text { Guilin, } \\
\text { Guangxi }\end{array}$ & $\begin{array}{l}\text { Western } \\
\text { Nanling } \\
\text { Mts. }\end{array}$ & 5 & $25.61^{\mathrm{O}} \mathrm{N}$ & $109.90^{\circ} \mathrm{E}$ & 852 & $0.38 / 0$ \\
\hline 9 & NLW3 & $\begin{array}{l}\text { Dupoxiang, } \\
\text { Huai- } \\
\text { hua, } \\
\text { Hunan }\end{array}$ & $\begin{array}{l}\text { Western } \\
\text { Nanling } \\
\text { Mts. }\end{array}$ & 13 & $26.07^{\mathrm{O}} \mathrm{N}$ & $109.47^{\circ} \mathrm{E}$ & $612-657$ & $0.32 / 0$ \\
\hline 10 & NLW4 & $\begin{array}{l}\text { Nanshan } \\
\text { Log Yard, } \\
\text { Shaoyang, } \\
\text { Hunan }\end{array}$ & $\begin{array}{l}\text { Western } \\
\text { Nanling } \\
\text { Mts. }\end{array}$ & 14 & $26.18^{\mathrm{O}} \mathrm{N}$ & $110.19^{\circ} \mathrm{E}$ & $611-703$ & $0.32 / 0$. \\
\hline 11 & NLW5 & $\begin{array}{l}\text { Mao'ershan } \\
\text { National } \\
\text { Nature } \\
\text { Reserve, } \\
\text { Guilin, } \\
\text { Guangxi }\end{array}$ & $\begin{array}{l}\text { Western } \\
\text { Nanling } \\
\text { Mts. }\end{array}$ & 7 & $25.89^{\mathrm{O}} \mathrm{N}$ & $110.38^{\mathrm{o}} \mathrm{E}$ & $700-852$ & $0.35 / 0$. \\
\hline
\end{tabular}

TABLE 2 Analysis of Molecular Variance (AMOVA) results for global Fst statistics of C. chuniana .

\begin{tabular}{lllll}
\hline Source of variation & $d . f$. & Sum of squares & Variance components & Percentage of variation \\
\hline Among groups & 6 & 3367.488 & 37.06608 & $96.28 \%$ \\
Among populations within groups & 4 & 36.908 & $0.89979^{* *}$ & $2.34 \%$ \\
Within populations & 101 & 53.747 & $0.53215^{* *}$ & $1.38 \%$ \\
Total & 111 & 3458.143 & 38.49802 & \\
Fixation Indices & $F s c: 0.6284^{* *}$ & Fst: $0.9862^{* *}$ & $F c t: 0.9628$ & \\
\hline
\end{tabular}


**: $P<0.001 ; F c t$, difference among groups;Fsc, differences among collections within groups; Fst , differences among all collections; d.f., degrees of freedom.

\section{FIGURE LEGENDS}

FIGURE 1 Map of southeastern China, showing the sampling locations of $C$. chuniana populations used in this study. The mountain ranges involved in the study are shown in orange shadows. Populations sampled in the Nanling Mts. are indicated with black circles; populations in the east are indicated with triangles. Vicariance events detected in S-DIVA are shown with blue lines. The key at bottom right indicates elevational ranges. Additional accession information is given in Table 1.

FIGURE 2 Potentially suitable areas for $C$. chunianapredicted by ecological niche modeling (ENM) and corresponding variation in temperature. Four different periods were applied, i.e., the Last Interglacial (LIG), the Last Glacial Maximum (LGM), the Middle Holocene (MH), and current. Suitable and unsuitable habitats are indicated in red and grey, respectively, where red represents the habitat suitability (occurrence probability) higher than $44.93 \%$. The temperature variations in each period are indicated in the gray boxes. (a) LIG; arrows point to relevant mountain ranges. The temperature during secondary contact $\left(T_{S E C}\right)$ is indicated. (b) Potentially suitable areas projected in comparison with a layer of GIS-based vegetation map at LGM. Numbers 1-8 represent different vegetation types at the LGM: 1, tropical thorn scrub and scrub woodland; 2, open boreal woodland; 3, semi-arid temperate woodland or scrub; 4, steppetundra; 5 , polar and alpine desert; 6 , temperate desert; 7 , forest steppe; and 8, dry steppe. (c) The simulated distribution range at MH. (d) The current potential distribution range, with black dots representing localities based on herbarium specimen data and samples collected for the present study. The most influential factors are listed in Table S1.

FIGURE 3 Phylogenetic tree of $C$. chuniana populations based on maximum-likelihood (ML) method. Bootstrap percentages (>50) in the ML tree are indicated above the branches. Cercis chingii was used as the outgroup.

FIGURE 4 Chronogram of the Bayesian tree for divergence time estimates, population structural clustering and ancestral area reconstruction. Branch lengths were transformed via Markov chain Monte Carlo (MCMC) simulations in the Bayesian time estimation. The light blue bars indicate $95 \%$ confidence intervals. Individuals assigned to different clusters in FastStructure are shown in corresponding colours with $K=2,3$ and 7 , with 7 as the optimal value. In the S-DIVA analysis, colour legends indicate different geographical regions and ancestral areas. Vicariance events (V1-V6) with high probabilities (P [?] 0.70), are shown for nodes. Populations in the Nanling Mts. are distinguished within the dotted line frame. Time scale bar is shown at the bottom. Various glacial and interglacial periods are indicated by the braces, the former of which is below the bar while the latter above the bar.

FIGURE 5 Schematic representation of the best fit demographic models investigated in our study. Model names and the parameters correspond to those in Tables S2 and S3, respectively. The left vertical line shows time $(\mathrm{Ma})$. Time of divergence $\left(T_{D I V}\right)$ and secondary contact $\left(T_{S E C}\right)$ are indicated as dashed lines, with the corresponding glacial or interglacial periods shown on the right. The top grey box represents the ancestral populations with effective population size. The current population sizes are shown at the bottom after the split between the Nanling Mts. (NL) and the eastern mountains (ES). The migration directions and corresponding rates $\left(M_{E S}\right)$ in individual migrants per generation are shown between NL and ES. 

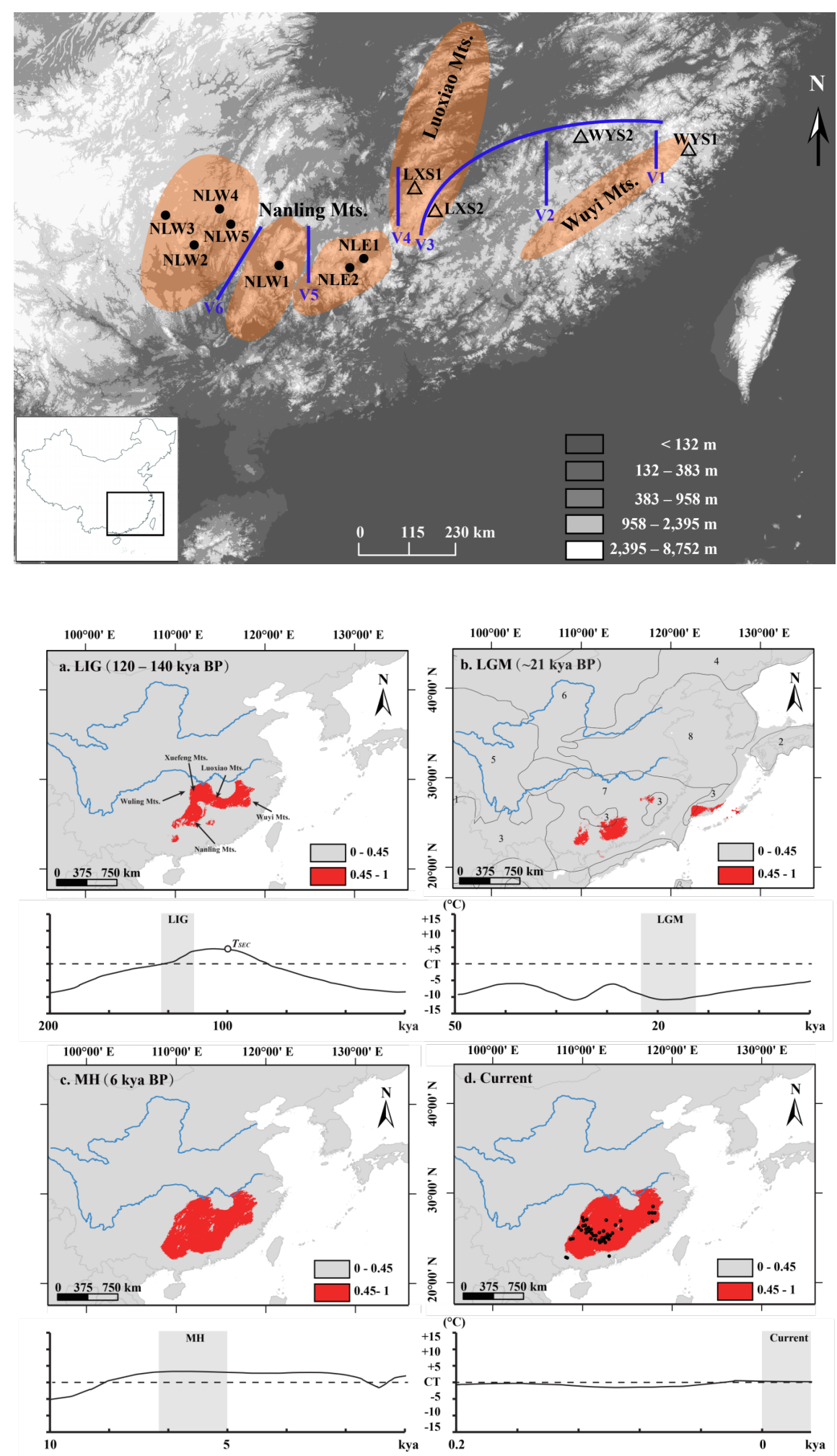

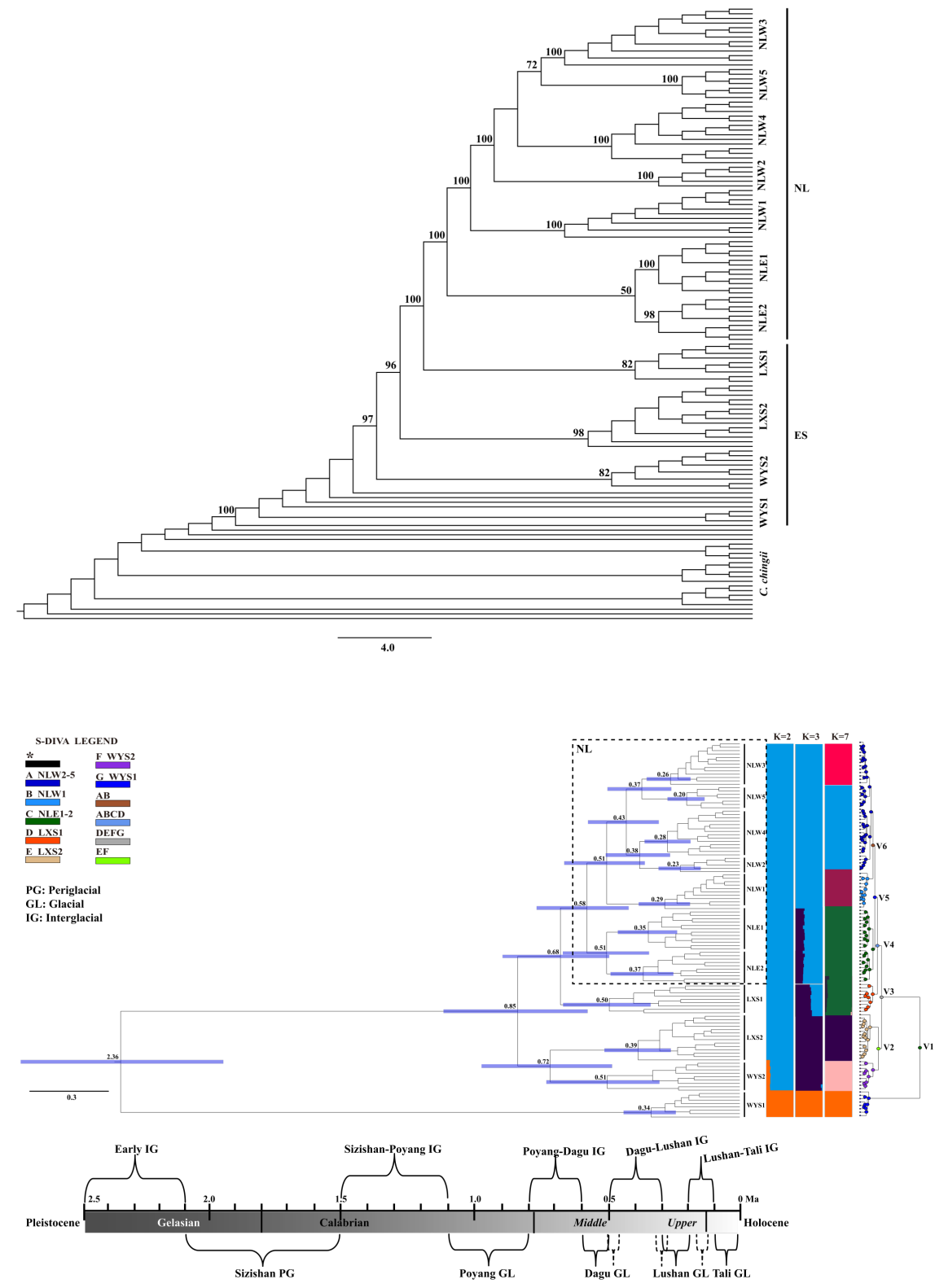

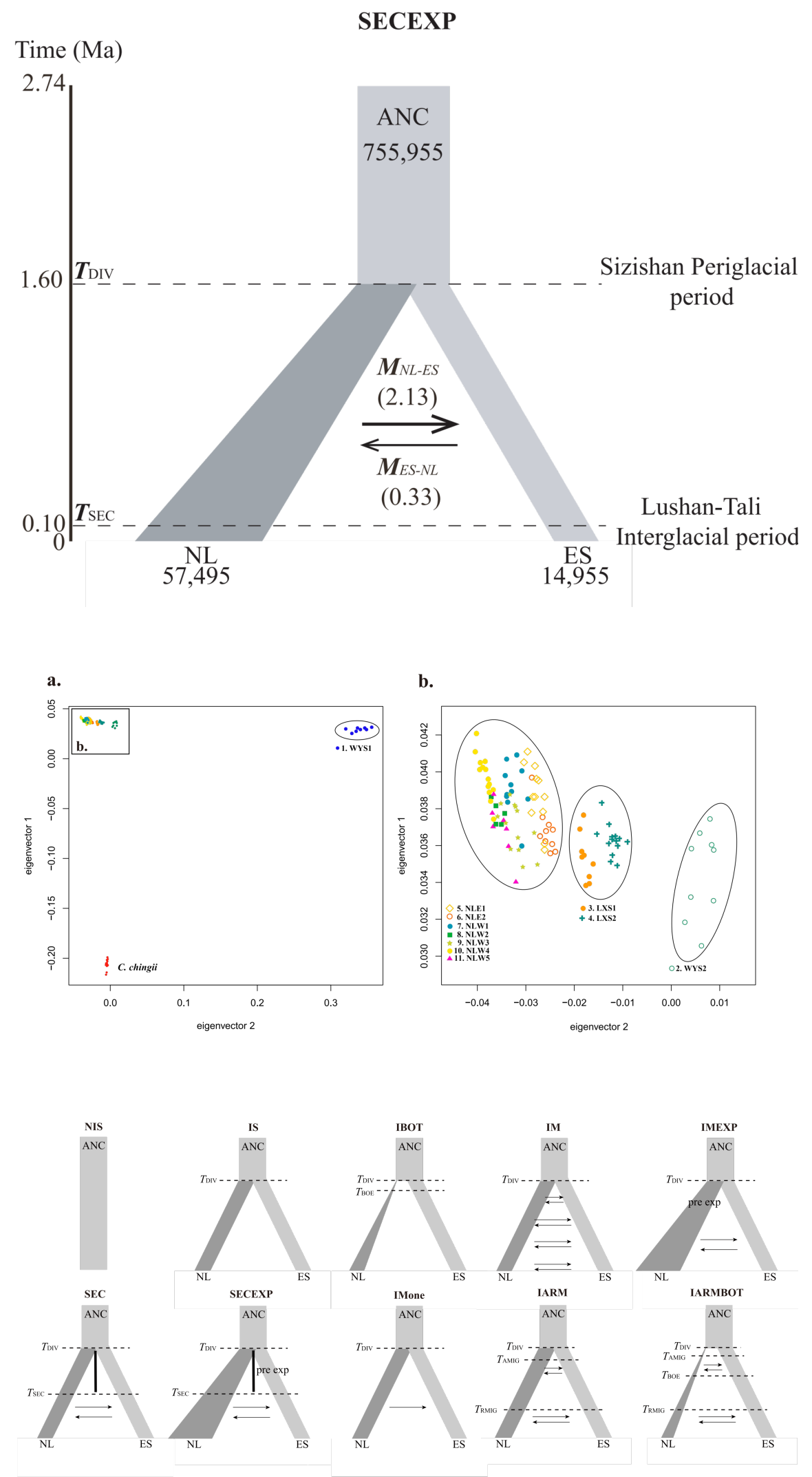